\title{
Simple and Improved Visible Spectrophotometric Method for Determination of Paracetamol Using Sodium Nitroprusside Chromogenic Reagent
}

\author{
SHIVAJI R. LABHADE ${ }^{1^{*}}$, KAILAS R. LABHADE ${ }^{2}$ and VISHWAS B. GAIKWAD \\ ${ }^{1}$ Department of Chemistry, K.T.H.M. College, Gangapur Road, Shivajinagar, \\ Nashik- 422 002, India \\ ${ }^{2}$ Department of Chemistry, S.V.K.T. Arts, Science and Commerce College, Deolali Camp, \\ Nashik- 422 401, India \\ ${ }^{3}$ Director, BCUD, Savitribai Phule Pune University, Ganeshkhind, Pune-411 007, \\ Maharashtra State, India \\ srlabhade3571@rediffmail.com
}

Received 15 January 2015 / Accepted 11 February 2015

\begin{abstract}
A simple, rapid and improved visible spectrophotometric method has been proposed for determination of paracetamol ( $N$-acetyl-p-aminophenol) in bulk drug. The experiment is based on the alkaline hydrolysis of paracetamol (PCT) to $p$-aminophenol (PAP) at elevated temperature and subsequent derivatization of PAP with sodium nitroprusside (SNP) at room temperature to produce an intense green colored $N$-nitrosyl- $O$-nitrosyl- $p$-aminophenol chromophore for direct determination of PCT at $685 \mathrm{~nm}$. The molar absorptivity and Sandell's sensitivity are observed as $5.933 \times 10^{4}$ $\mathrm{L} . \mathrm{mol}^{-1} . \mathrm{cm}^{-1}$ and $0.0252 \mu \mathrm{g}$. $\mathrm{cm}^{-2}$ respectively for the chromophore. Beer's law is obeyed over the concentration range of $15-120 \mu \mathrm{g}$ with linear regression equation as $\mathrm{A}=0.009+0.003 \mathrm{C}(\mu \mathrm{g}$ at $10 \mathrm{~mL}$ dilution). The percent recovery was found in the range $100.07-100.60 \%$. The average of relative error and relative standard deviation are observed as $0.252 \%$ and $0.406 \%$ respectively. Reaction mechanism and reaction stoichiometry of the chromophoric reaction are discussed. The parameters with regard to determination of paracetamol by proposed method are optimized. Drugs like ibuprofen, aspirin and metformin do not interfere hence the proposed method is suitable for determination of PCT impurity in the said drugs.
\end{abstract}

Keywords: Paracetamol, $N$-acetyl-p-aminophenol, $p$-Aminophenol, $N$-nitrosyl-O-nitrosyl-p-aminophenol, Sodium nitroprusside

\section{Introduction}

Paracetamol (PCT), chemically 4-hydroxy acetanilide ${ }^{1}$, 4-hydroxy $N$-phenyl acetamide, or $N$-acetyl-p-aminophenol has analgesic and antipyretic activity ${ }^{1,2}$. It is official in Indian Pharmacopoeia $^{3}$, British Pharmacopoeia ${ }^{4}$ and United States Pharmacopoeia ${ }^{5}$. It is also prescribed to relief the symptoms of fever, cough, cold and mild to moderate pain of everyday life 
like headache, backache muscular aches, joint pain and others ${ }^{6,7}$. The overdose of PCT can cause fulminating hepatic necrosis and could result in certain toxic effects ${ }^{8}$. Therefore, determination of PCT in pharmaceuticals is of paramount importance.

Literature survey revealed many methods with different analytical techniques for individual or simultaneous determination of PCT in different sample types. The technique includes

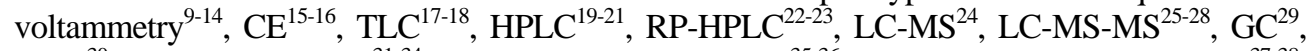
FTIR $^{30}$, spectrofluorimetry ${ }^{31-34}$, kinetic spectrophotometry ${ }^{35-36}$, derivative spectrophotometry ${ }^{37-38}$, indirect spectrophotometry ${ }^{39}$, direct spectrophotometry ${ }^{40-45}$ etc. The techniques other than spectrophotometry require lengthy procedures, highly sophisticated analytical instruments and some amount of the organic solvents contributing towards high cost of the analysis.

Spectrophotometry is the most common, convenient and favorite tool in analytical laboratories due to its inherent sensitivity and low costing. So, we aimed to report the original approach that allows a simple, rapid and improved spectrophotometric determination of PCT avoiding lengthy procedure and minimizing the use of hazardous chemicals. In addition, the effect (or interference) of some active drugs which are commonly used along with PCT in tablet formulations are studied in the determination of PCT by using SNP.

Sodium pentacyanonitrosylferrate(II) or sodium nitroprusside (SNP), $\mathrm{Na}_{2}\left[\mathrm{Fe}(\mathrm{CN})_{5} \mathrm{NO}\right]$ is a popular derivatization agent of analytically important for the detection and determination of wide variety of nucleophilic moieties such as primary or secondary aliphatic amines, aldoximes, ketones, nitrites, phenols, pyrroles, quinones, thiols, thioureas and uracils ${ }^{46-47}$. Many spectrophotometric methods adapted SNP as an analytical reagent in their applications, including the assays of paracetamol ${ }^{42}$, $\operatorname{rosoxacin}^{48}$, $\operatorname{streptomycin}^{49}$, cefradine $^{50}$ and methanol ${ }^{51}$. Recently we have utilized SNP as chromogenic reagent for selective identification ${ }^{52}$ and determination ${ }^{53}$ of metformin by spectrophotometry.

Earlier spectrophotometric method ${ }^{42}$ for determination of PCT involved use of SNP reagent along with potassium ferricyanide and sodium hydroxide. In this experiment reaction time of 30 minutes and constant temperature of $35^{\circ} \mathrm{C}$ was required for generation of chromophore of PCT. The reaction temperature above $35{ }^{\circ} \mathrm{C}$ decomposes the SNP reagent and chromophoric system thus was produced; consequently intensive care is required for determination of PCT by this method $^{42}$. The present study aimed to develop a spectrophotometric method for determination of PCT based on its alkali hydrolysis PAP at elevated temperature and subsequent derivatization of PAP with SNP to produce an intense green colored $N$-nitrosyl- $O$-nitrosyl-p-aminophenol chromophore for direct determination of PCT at $685 \mathrm{~nm}$.

\section{Experimental}

A Shimadzu double beam UV-Visible spectrophotometer (UV-1800) with software UVProbe 2.33 and $10 \mathrm{~mm}$ matched quartz silica cells was used for all spectral/absorbance measurements.

\section{Reagent and materials}

All the chemicals were of analytical grade or pharmaceutical grade and used without further purification. The required reagents were prepared in distilled water and stored in the amber colored bottles.

1. A fresh $1.0 \times 10^{-2} \mathrm{~mol} \mathrm{~L}^{-1} \mathrm{SNP}$ solution was prepared by dissolving $1.490 \mathrm{~g}$ of $\mathrm{Na}_{2}\left[\mathrm{Fe}(\mathrm{CN})_{5} \mathrm{NO}\right] \cdot 2 \mathrm{H}_{2} \mathrm{O}$ in $500 \mathrm{~mL}$ of distilled water.

2. A $5.0 \mathrm{~mol} \mathrm{~L}^{-1} \mathrm{NaOH}$ solution was prepared by dissolving $100 \mathrm{~g} \mathrm{NaOH}$ in $500 \mathrm{~mL}$ of distilled water. 
3. A standard $1.0 \times 10^{-3} \mathrm{~mol} \mathrm{~L}^{-1}$ stock solution of PCT was prepared by dissolving $76 \mathrm{mg}$ of pharmaceutical grade PCT (151.163 $\left.\mathrm{g} \mathrm{mol}^{-1}\right)$ in $500 \mathrm{~mL}$ of distilled water. A $2.0 \times 10^{-4}$ mol $\mathrm{L}^{-1}$ working solution of PCT was prepared by diluting this stock solution with distilled water.

\section{Recommended procedure}

Aliquots of 0.5 to $4.0 \mathrm{~mL}$ of $2.0 \times 10^{-4} \mathrm{~mol} \mathrm{~L}^{-1}$ (containing 15.0-120.0 $\mu \mathrm{g}$ ) of PCT were diluted to $4.0 \mathrm{~mL}$ with distilled water and transferred to $25 \mathrm{~mL}$ calibrated flasks containing $4.0 \mathrm{~mL}$ of $5.0 \mathrm{M} \mathrm{NaOH}$ solution. The flasks were heated for 15 minutes on a boiling water bath and cooled to room temperature by placing them in a steam of running water. Then $2.0 \mathrm{~mL}$ of $1.0 \times 10^{-2} \mathrm{~mol} \mathrm{~L}^{-1}$ of SNP solution was added to each flask. The reaction mixtures were thoroughly shaken and left for 15 minutes for complete development of chromophoric system. The absorbance of solutions was measured at $685 \mathrm{~nm}$ at $10 \mathrm{~mL}$ dilution against the reagent blank. The calibration curve was constructed by plotting the absorbance values against the concentration of the PCT. The amount of the PCT in the sample was computed either from calibration curve or regression equation.

\section{Results and Discussion}

The alkaline hydrolysis of the PCT to PAP was reported in the literature ${ }^{54}$. Preliminary tests revealed that at room temperature (in $10 \mathrm{M} \mathrm{NaOH}$ ) PCT undergo slow hydrolysis to PAP, as a result progressive increase in green color was observed when reaction product was simultaneously derivatized with SNP reagent. Accordingly, this route was not found to be adequate for quantitative determination of PCT through measurement of concrete absorbance reading. At normal temperature full color development took 5-6 hours even though $10 \mathrm{M} \mathrm{NaOH}$ was for hydrolysis of PCT. This time dependent chromogenic reaction was quantitatively carried out by quantitative hydrolysis of PCT to PAP by heating alkaline solution of PCT with $\mathrm{NaOH}$ on boiling water bath for 15 minutes.

\section{Wavelength for analysis}

According to the procedure, the absorption spectrum of the product formed by the reaction between SNP and the hydrolyzed product of the PCT (viz. PAP) in alkaline medium has been recorded for different concentration of the PCT (Figure 1). Absorption spectra (4-11) were obtained 15 minutes after the initiation of reaction of the hydrolyzed product with SNP reagent. From the spectra it can be seen that the wavelength of maximum molar absorptivity of the green colored $N$-nitrosyl-O-nitrosyl-p-aminophenol chromophore is at $685 \mathrm{~nm}$. Except the reaction product, all the reagents and reagent blank solution are transparent at this wavelength.

\section{Mechanism of the chromogenic reaction}

Hydrolysis of PCT to PAP with $\mathrm{NaOH}$ (at $95^{\circ} \mathrm{C}$ ) followed by derivatization of PAP with SNP (at $25^{\circ} \mathrm{C}$ ) to form a green colored $N$-nitrosyl- $O$-nitrosyl- $p$-aminophenol chromophore is the basis of determination of PCT by this method, which is reported in the Scheme 1.

The PAP (obtained by hydrolysis PCT with $\mathrm{NaOH}$ ) exhibited significant reactivity with SNP. Both phenolic hydroxyl and amine groups of PAP have nucleophilicity and tend to attack on the electron deficiency center in nitrosyl groups of SNP molecules. This results in nucleophilic substitution reaction as reported in Scheme 1. The development of an intense green color to chromophore is due to increase in conjugation of double bonds by means of electron donor oxygen as well as nitrogen atom of PAP and electron acceptor nitrosyl groups 
of SNP molecules. Reactivity of SNP in $\mathrm{NaOH}$ is because of formation of $\left[\mathrm{Fe}(\mathrm{CN})_{5} \mathrm{NO}(\mathrm{OH})\right]^{3-}$ active species ${ }^{51,55}$. It is interesting to know that the chromogenic reaction does not occurred in ammonia solution because of the ability of the ammonia to form $\left[\mathrm{H}_{3} \mathrm{~N}-\mathrm{NO}\right]^{+}$species, Consequently ammonia mask the activity of nitrosyl ion of SNP.

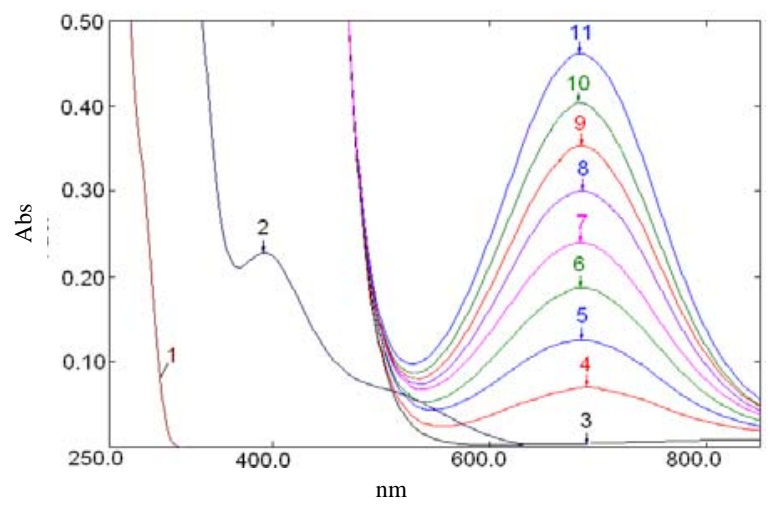

Figure 1. Absorption spectrum obtained at $10 \mathrm{~mL}$ dilution (against distilled water) of $2.0 \times 10^{-4} \mathrm{M}$ of PCT solution (1), of $1.0 \times 10^{-2} \mathrm{~mol} \mathrm{~L}^{-1}$ of SNP solution (2), reagent blank solution containing $4.0 \mathrm{~mL}$ of $5.0 \mathrm{M} \mathrm{NaOH}$ and $2.0 \mathrm{~mL}$ of $1.0 \times 10^{-2} \mathrm{~mol} \mathrm{~L}^{-1} \mathrm{SNP}$ (3) and their reaction product with $1.0 \times 10^{-4}$ to $8.0 \times 10^{-4} \mathrm{M}(4-11)$ of PCT.
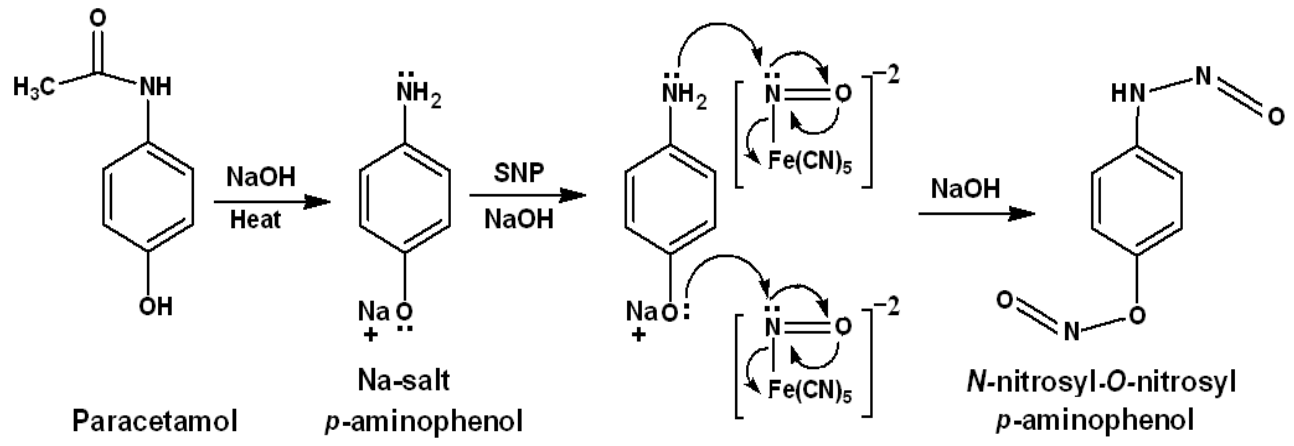

Scheme 1. The reaction mechanism involved in generation of chromophore of the PCT

\section{Reaction stoichiometry}

The reaction stoichiometry of the hydrolyzed product of PCT (viz. PAP) with SNP reagent was proved by varying the concentration of $0.001 \mathrm{M}$ SNP and $0.001 \mathrm{M}$ PCT. In first case according to procedure the reaction product was obtained in $6.0 \mathrm{ml} 5.0 \mathrm{M} \mathrm{NaOH}$ with the fixed concentration of PCT $(4.0 \mathrm{~mL}$ of $0.001 \mathrm{M})$ and changing the concentration of $0.001 \mathrm{M}$ SNP $(1.0 \mathrm{~mL}$ to $12.0 \mathrm{~mL})$. In second case the reaction product was obtained with the fixed concentration of SNP $(5.0 \mathrm{~mL}$ of $0.001 \mathrm{M})$ and changing the concentration of $0.001 \mathrm{M}$ PCT $(0.5 \mathrm{~mL}$ to $5.0 \mathrm{~mL})$.

The results of these studies are reported in Figure 2 and Figure 3 illustrates that the stoichiometric ratio of the reaction between PCT and SNP is 1:2. It is presumably that phenolic hydroxyl as well as amine groups of the PAP reacts with two nitrosyl groups of two SNP molecules to form the $N$-nitrosyl- $O$-nitrosyl- $p$-aminophenol chromophore. Hence, the reaction mechanism shown in Scheme 1 is justified. 


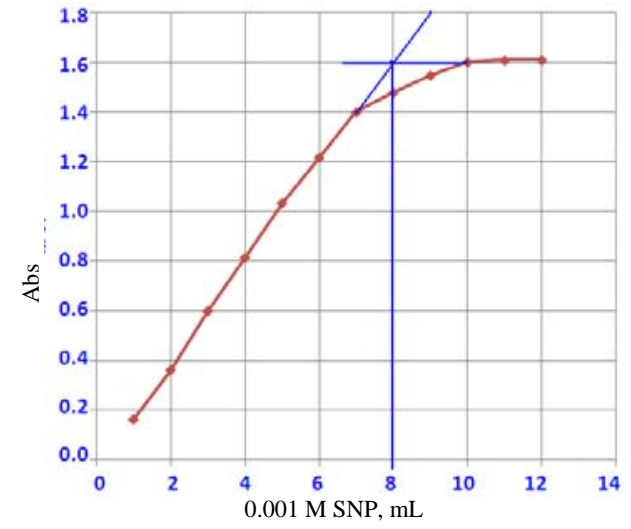

Figure 2. Reaction stoichiometry by variation in concentration of SNP reagent

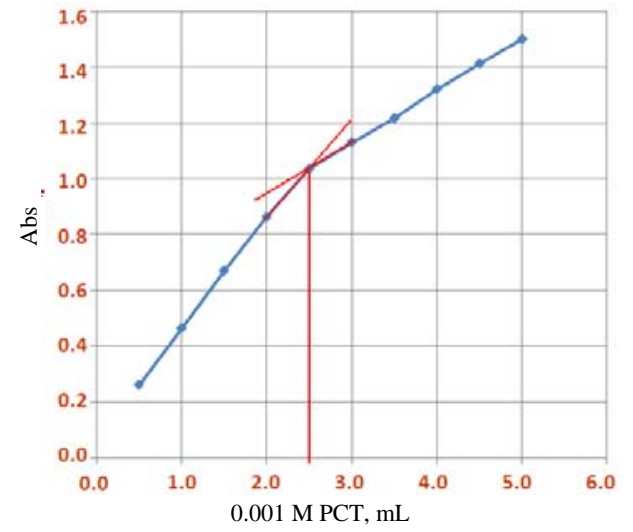

Figure 3. Reaction stoichiometry by variation in concentration of PCT analyte

\section{Optimization of chromogenic reaction conditions}

The chemical parameters for the method development was established by varying the parameters one at a time and keeping the others fixed and observing the effect produced on the absorbance of the green colored product.

\section{Concentration of $\mathrm{NaOH}$ for hydrolysis of PCT}

Hydrolysis of PCT to PAP by $\mathrm{NaOH}$ is the first step in the determination of PCT by this method, so concentration of $\mathrm{NaOH}$ directly determines absorbance of the solutions. The determination of concentration of $\mathrm{NaOH}$ for quantitative hydrolysis of PCT, $2.0 \mathrm{~mL}$ aliquots containing $160 \mu \mathrm{g}$ of PCT were transfer to calibrated flasks containing $0.5,1.0,2.0,3.0,4.0$, 5.0, 6.0 and $7.0 \mathrm{~mL}$ of $5.0 \mathrm{M} \mathrm{NaOH}$. After treatment of the solutions according to recommended procedure, the absorbance was measured at $685 \mathrm{~nm}$. From the results shown in Figure 4, it can be concluded that $5.0 \mathrm{~mL}$ of $5.0 \mathrm{M} \mathrm{NaOH}$ is sufficient for complete hydrolysis of $160 \mu \mathrm{g}$ of PCT. Therefore, $4.0 \mathrm{~mL}$ of $5.0 \mathrm{M} \mathrm{NaOH}$ was used for hydrolysis of PCT having concentration up to $120 \mu \mathrm{g}$.

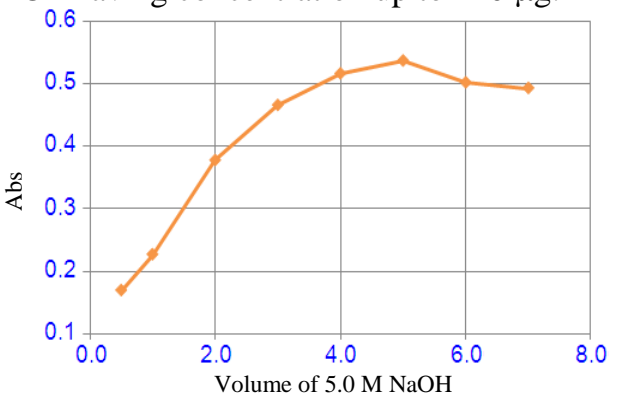

Figure 4. Determination of conc. of $\mathrm{NaOH}$ for hydrolysis of PCT at $95{ }^{\circ} \mathrm{C}$

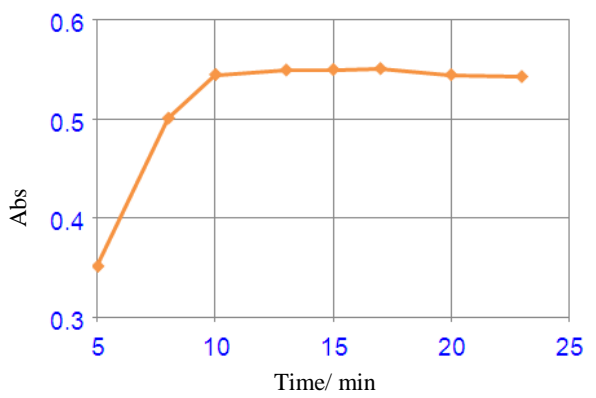

Figure 5. Determination of hydrolysis time for PCT at $95{ }^{\circ} \mathrm{C}$

\section{Hydrolysis time of PCT}

Keeping reaction temperature constant $\left(95^{\circ} \mathrm{C}\right)$, different heating intervals such as $5,8,10$, 13, 15, 17, 20 and 23 minutes were selected for hydrolysis of $160 \mu \mathrm{g}$ of PCT in $5.0 \mathrm{~mL}$ of $5.0 \mathrm{M} \mathrm{NaOH}$. After treatment as per recommended procedure, the absorbance of solutions 
was measured at $685 \mathrm{~nm}$. The Figure 5 indicates effect of heating time on the hydrolysis of PCT. From this figure it is clear that, when heating time (at $95{ }^{\circ} \mathrm{C}$ ) is less than 10 minutes, absorbance is less while subsequent increase in heating time increases absorbance and it remain nearly constant after 15 minutes.

\section{Concentration of SNP reagent}

Sodium nitroprusside in basic medium functions as chromogenic reagent for PAP. Therefore, concentration of SNP directly determines the absorbance of the reaction product. The amount of SNP required for complete derivation of PAP which released in hydrolysis of $160 \mu \mathrm{g}$ of PCT, was determined by submitting $0.5,1.0,2.0,3.0,4.0$ and $5.0 \mathrm{~mL}$ of $1.0 \times 10^{-2} \mathrm{M}$ SNP to six different test solutions. The absorbance of these six solutions at $685 \mathrm{~nm}$ was observed as $0.5836,0.6085,0.6139,0.5891,0.5863$ and 0.5789 respectively. The maximum absorbance (0.6139) observed for $2.0 \mathrm{~mL}$ of $1.0 \times 10^{-2} \mathrm{M}$ SNP. So, $2.0 \mathrm{~mL}$ of $1.0 \times 10^{-2} \mathrm{M} \mathrm{SNP}$ reagent was found adequate for assay PCT up to $160 \mu \mathrm{g}$.

\section{Chromophore development time}

The intensity of chromogen is governed by rate of derivatization reaction of both phenolic and amine groups of PAP with the nitrosyl groups of SNP molecules. The time for full development of chromophore was determined by measuring the absorbance of the reaction product against time. The absorbance-time curves (Figure 6) illustrate that, the solution of reaction product reaches to a state of maximum absorbance within 10-12 minutes (time measured from the addition of SNP) and thereafter absorbance remains nearly constant. Therefore, absorbance measurement was carried out 15 minutes after the initiation of reaction between hydrolyzed product of PCT and SNP.

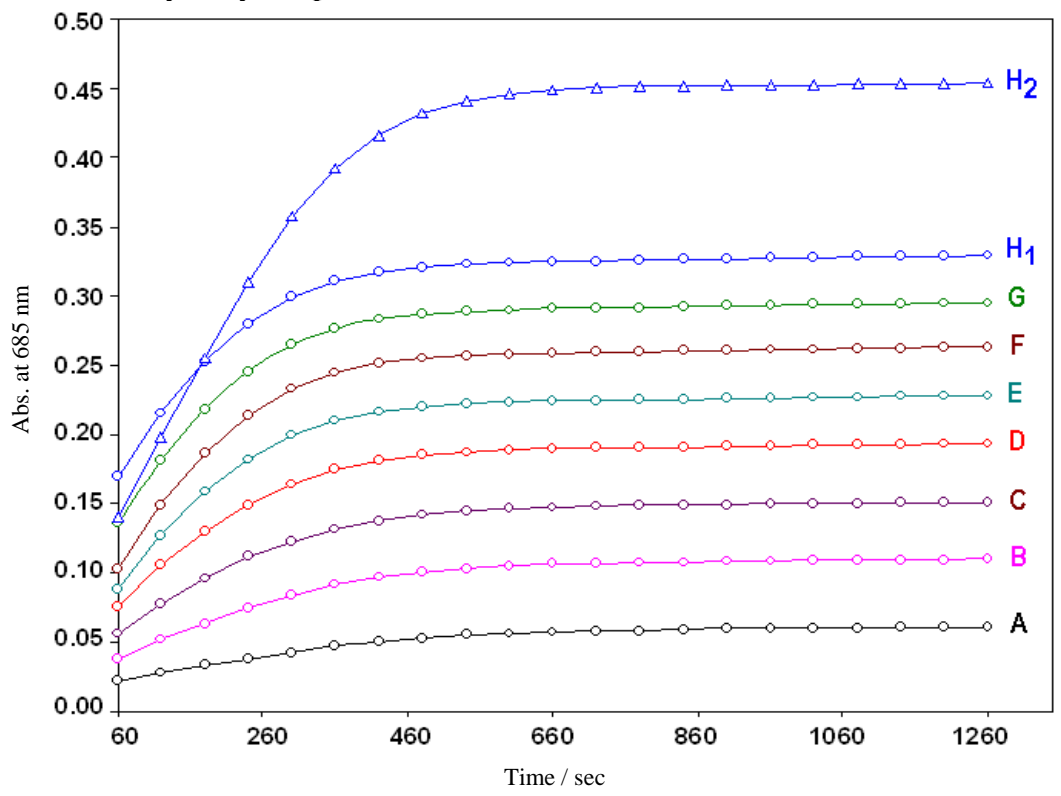

Figure 6. Absorbance-time curves $\mathrm{A}$ to $\mathrm{H}_{1}$ obtained with initiation of chromogenic reaction at $20,40,60, \ldots$ upto $160 \mathrm{~min}$. respectively for hydrolyzed product of $15,30,45, \ldots$ and $120 \mu \mathrm{g}$ of PCT. The curves $\mathrm{H}_{1}$ and $\mathrm{H}_{2}$ are obtained by initiation of chromogenic reaction at $160 \mathrm{~min}$. and $20 \mathrm{~min}$. after the hydrolysis of $120 \mu \mathrm{g}$ of PCT 


\section{Non suitability of kinetic method}

The absorbance of the reaction product showed progressive increase with time (Figure 6). Therefore, for testing the suitability of the kinetic method, $4.0 \mathrm{~mL}$ aliquots containing $15-120 \mu \mathrm{g}$ of PCT were digested simultaneously (at $95{ }^{\circ} \mathrm{C}$ for $15 \mathrm{~min}$.) with $4.0 \mathrm{~mL}$ of $5.0 \mathrm{M} \mathrm{NaOH}$ and cooled to room temperature. Absorbance of these solutions was supervised with time by initiation of chromogenic reaction (with the addition of SNP) at 20, 40,60,... upto $160 \mathrm{~min}$. respectively for hydrolyzed product of $15,30,45, \ldots$ and $120 \mu \mathrm{g}$ of PCT. These results illustrate that, the absorbance when measured by using kinetic data (as obtained in Figure 6) does not shows linearity with the concentration of paracetamol.

Furthermore, the curves $\mathrm{H}_{1}$ and $\mathrm{H}_{2}$ are obtained by initiation of chromogenic reaction after $160 \mathrm{~min}$. and $20 \mathrm{~min}$. of the hydrolyzed product of $120 \mu \mathrm{g}$ of PCT. The curve $\mathrm{H}_{1}$ and $\mathrm{H}_{2}$ obtained for same concentration of PCT showed difference in absorbance. These absorbances are obtained at $120 \mathrm{~min}$. and $20 \mathrm{~min}$. respectively after the hydrolysis of PCT. The curve $\mathrm{H}_{1}$ in Figure 6 indicates hydrolyzed product of PCT when kept for a long time (in $\mathrm{NaOH}$ ) undergoes slow oxidation and forms $p$-benzoquinoneimine. In $p$-benzoquinoneimine only nitrogen from -NH- group reacts with nitrosyl group of SNP. Consequently, the reaction stoichiometry changes from 1:2 to $1: 1$ which directly reflect the decrease in absorbance. For the same reason curve A to $\mathrm{H}_{1}$ obtained for 15 to $120 \mu \mathrm{g}$ of PCT does not showed linearity of concentration with the absorbance. It is observed that due to laps in time during the absorbance measurement, kinetic method is not suitable route for determination of PCT by proposed procedure.

Table 1. Summary for the optimization of variables affecting the reaction of PCT with SNP employed in the development of the proposed spectrophotometric method

\begin{tabular}{lcc}
\hline Variable & Studied Range & Optimum \\
\hline Concentration range of PCT & $15.0-120.0 \mu \mathrm{g}$ & $15.0-120.0 \mu \mathrm{g}$ \\
Volume of $1.0 \times 10^{-2} \mathrm{M}$ SNP & $0.5-5.0 \mathrm{~mL}$ & $2.0 \mathrm{~mL}$ \\
Volume of $5.0 \mathrm{M} \mathrm{NaOH}$ & $0.5-7.0 \mathrm{~mL}$ & $4.0 \mathrm{~mL}$ \\
Hydrolysis temperature of PCT by NaOH & $95^{\circ} \mathrm{C}$ & $95{ }^{\circ} \mathrm{C}$ \\
Hydrolysis time of PCT at $95^{\circ} \mathrm{C}$ & $5-23 \mathrm{~min}$. & $15 \mathrm{~min}$. \\
Reaction temperature of PAP with SNP & $25^{\circ} \mathrm{C}$ & $25^{\circ} \mathrm{C}(\mathrm{RT})$ \\
Time of chromogen development & $0-21 \mathrm{~min}$ & $10 \mathrm{~min}$ \\
Time of absorbance measurement & $0-21 \mathrm{~min}$ & $15 \mathrm{~min}$ \\
(after addition of SNP reagent) & & \\
\hline
\end{tabular}

\section{Sensitivity and Linearity of the method}

Sensitivity of the method in terms of the molar absorptivity $(\varepsilon)$ and Sandell's sensitivity ${ }^{56}$ was determined by quantification of PCT in the range $1.0 \times 10^{-4}$ to $8.0 \times 10^{-4} \mathrm{M}$ (viz.15 to $120 \mu \mathrm{g}$ ) using $4.0 \mathrm{~mL}$ of $5.0 \mathrm{M} \mathrm{NaOH}$ and $2.0 \mathrm{~mL}$ of $1.0 \times 10^{-2} \mathrm{~mol} \mathrm{~L}^{-1} \mathrm{SNP}$ at $10 \mathrm{~mL}$ dilution. The concentration of PCT and maximum absorbance of its reaction product (c.f. Figure 1) are: $0.0 \times 10^{-4} \mathrm{M}(\mathrm{A}=0.010) ; 1.0 \times 10^{-4} \mathrm{M}(\mathrm{A}=0.075) ; 2.0 \times 10^{-4} \mathrm{M}(\mathrm{A}=0.131) ; 3.0 \times 10^{-4} \mathrm{M}(\mathrm{A}=$ $0.190) ; 4.0 \times 10^{-4} \mathrm{M}(\mathrm{A}=0.244) ; 5.0 \times 10^{-4} \mathrm{M}(\mathrm{A}=0.301) ; 6.0 \times 10^{-4} \mathrm{M}(\mathrm{A}=0.355) ; 7.0 \times 10^{-4} \mathrm{M}$ $(A=0.413) ; 8.0 \times 10^{-4} \mathrm{M}(\mathrm{A}=0.468)$. After correcting the absorbance values (by subtracting the absorbance of the blank solution), when plotted against the concentration of PCT ( $\mu \mathrm{g})$, a linear relationship was found between the absorbance and concentration of the PCT in the range 
15.0-120.0 $\mu \mathrm{g}$. A calibration curve of absorbance against the concentration of PCT gives the linear regression equation as $\mathrm{A}=0.009+0.003 \mathrm{C}\left(\mu \mathrm{g} \cdot \mathrm{mL}^{-1}\right)$ with a regression coefficient $\left(r^{2}=0.999\right)$. The average molar absorptivity for green colored product at $685 \mathrm{~nm}$ is $5.933 \times 10^{4}$ Lit $\mathrm{Mol}^{-1} \mathrm{~cm}^{-1}$. In a cell of $1.0 \mathrm{~cm}$ path length, the unit concentration of PCT (viz. $1.0 \mu \mathrm{g}$ ) gives an average absorbance value equal to 0.0396; hence, $0.0252 \mu \mathrm{g}$ (Sandell's sensitivity) concentration of PCT changes absorbance value by 0.001 unit. The molar absorptivity value thus obtained in this experiment when compared with the reported value ${ }^{42}$ for determination of PCT, interpret that proposed method of determination of PCT is more sensitive. The sensitivity or higher molar absorptivity is because of derivatization of both phenolic hydroxyl and amine groups of the hydrolyzed product (PNP) by two nitrosyl groups of two SNP molecules.

Table 2. Analytical and optical parameters for spectrophotometric determination of PCT

\begin{tabular}{cc}
\hline Statistical Parameter Tested & Parameter Values \\
\hline Measurement wavelength, $\lambda_{\max }$ & $685 \mathrm{~nm}$ \\
Reaction stoichiometric ratio PCT: SNP & $1: 2$ \\
Beer's law limit & $15.0-120.0 \mu \mathrm{g}$ \\
Molar absorptivity & $5.933 \times 10^{4} \mathrm{Lit} . \mathrm{Mol}^{-1} \cdot \mathrm{cm}^{-1}$ \\
Sandell's sensitivity & $0.0253 \mu \mathrm{gm}^{-2}$ \\
Regression equation & $\mathrm{A}=9.0 \times 10^{-3}+3.0 \times 10^{-3} \mathrm{C}$ \\
Regression coefficient $\left(\mathrm{r}^{2}\right)$ & 0.999 \\
\hline
\end{tabular}

Apart from this, with the use of $4.0 \mathrm{~mL}$ of $5.0 \mathrm{M} \mathrm{NaOH}$ and $2.0 \mathrm{~mL}$ of $1.0 \times 10^{-2} \mathrm{~mol} \mathrm{~L}^{-1}$ SNP at $10 \mathrm{~mL}$ dilution, the test solutions having lower concentration of PCT (15-30 $\mu \mathrm{g})$ showed slight increase in the value of $\varepsilon$. This is because of the yellow color of the unused reagent which picks up the absorbance of these test solutions. Solutions of PCT with higher concentration consumes the maximum of this reagent.

\section{Interference study}

In tablet formulations PCT is usually associated with ibuprofen and aspirin active drugs. Experimentally an alkaline solution of ibuprofen and aspirin when tested according to procedure for development of the green colored chromophore, were showed negative test with the SNP reagent. Also, metformin in alkaline medium generates green color ${ }^{52-53}$ with SNP, but when the solution of metformin was heated with $\mathrm{NaOH}$ does not produce green color to the solution. Therefore, it can be concluded that, ibuprofen, aspirin and metformin do not interferes in the determination of PCT and hence proposed procedure is suitable for determination PCT impurities in these bulk drugs.

\section{Precision and Accuracy}

Precision and accuracy of the developed method was ascertained from the absorbance values obtained by actual determination (in Beer's law limit) of six replicates of a fixed amount of PCT. The percent of relative standard deviation and percent range of errors were calculated and presented in Table 3. Percent of relative standard deviation (\% RSD) was found to be less than 2, which indicate that the developed method is precise. The percentage recovery of the drug was found to be within the range of 100.07-100.60 and thus indicates that the developed method is accurate. 
Table 3. Evaluation of accuracy and precision in determination of PCT by the proposed method

\begin{tabular}{|c|c|c|c|c|c|c|c|}
\hline \multirow{2}{*}{\multicolumn{2}{|c|}{$\begin{array}{c}\text { PCT } \\
\mu \mathrm{g}\end{array}$}} & \multicolumn{3}{|c|}{ Accuracy } & \multicolumn{3}{|c|}{ Precision } \\
\hline & & \multirow{2}{*}{$\begin{array}{c}\text { Recovery, } \\
\%\end{array}$} & \multirow{2}{*}{$\begin{array}{l}\text { Absolute } \\
\text { Error }\end{array}$} & \multirow{2}{*}{$\begin{array}{l}\text { Relative } \\
\text { Error, \% }\end{array}$} & \multirow{2}{*}{$\begin{array}{c}\text { Average } \\
\text { Deviation }\end{array}$} & \multirow{2}{*}{$\begin{array}{l}\text { Relative Std. } \\
\text { Deviation, \% } \\
\end{array}$} & \multirow{2}{*}{$\begin{array}{l}\text { Standard } \\
\text { Deviation }\end{array}$} \\
\hline Taken & Found* & & & & & & \\
\hline 30.0 & 30.18 & 100.60 & 0.18 & 0.60 & 0.23 & 0.762 & 0.278 \\
\hline 45.0 & 45.07 & 100.16 & 0.07 & 0.16 & 0.24 & 0.533 & 0.280 \\
\hline 60.0 & 60.17 & 100.28 & 0.17 & 0.28 & 0.21 & 0.349 & 0.287 \\
\hline 75.0 & 75.05 & 100.07 & 0.05 & 0.07 & 0.15 & 0.199 & 0.187 \\
\hline 90.0 & 90.25 & 100.28 & 0.25 & 0.28 & 0.35 & 0.388 & 0.394 \\
\hline 105.0 & 105.12 & 100.12 & 0.12 & 0.12 & 0.22 & 0.206 & 0.264 \\
\hline \multicolumn{2}{|c|}{ Average: } & 100.25 & -- & 0.252 & -- & 0.406 & 0.282 \\
\hline
\end{tabular}

\section{Conclusion}

The proposed method is rapid and reproducible. It can be used in the routine analysis of paracetamol in bulk drug with reasonable accuracy and precision. The procedure employed for determination of PCT is quite simple and demonstrates successful use of SNP reagent (without any oxidizing reagent) for visible spectrophotometric determination of PCT through forming the $N$-nitrosyl- $O$-nitrosyl-p-aminophenol chromophore. The higher value for molar absorptivity revealed that proposed method is more improved, sensitive and suitable. Active drugs ibuprofen, aspirin and metformin do not interferes in the determination of PCT; hence proposed procedure is also suitable for determination PCT as an impurity said drug products. Apart from this, all analytical reagents used in this experiment are inexpensive, has excellent shelf life and available in all analytical laboratory. Also as compared with other methods, the proposed method needs neither the complicated apparatus, nor new reagents to be synthesized. Therefore, determination of PCT with SNP has got an important value and practical foreground.

\section{Acknowledgement}

The authors thank the authorities of UGC, WRO, Pune and BCUD, Savitribai Phule Pune University, Pune for providing the sizable funds under the minor research projects. Authors are also grateful to the Managing Committee of MVP Samaj Nashik and the Principal of the K.T.H.M. College, Nashik for providing the necessary infrastructure and instrumentations.

\section{References}

1. Budavari S, The Merck Index. $13^{\text {th }}$ Ed., Whitehouse Station, NJ: Merck and Co Inc; 2003.

2. Sweetman S C, Martindale, The Complete Drug Reference, 33 ${ }^{\text {rd }}$ Ed., London: Pharmaceutical Press, 2002.

3. Indian Pharmacopoeia. The Indian Pharmacopoeia Commission. Vol. 3. Ghaziabad: Govt. of India Ministry of Health and Family Welfare; 2007, 1514-6.

4. British pharmacopoeia. The Stationery Office on behalf of the Medicines and Healthcare products Regulatory Agency (MHRA) Vol. 2. Great Britain: The Department of Health; 2007, pp. 1575-7.

5. United States Pharmacopoeia. Rockville: United States Pharmacopoeial Convention, Inc; 2007, pp. 1269-70. 
6. Lipton R B, Bigal M E, Kolodner K B, Gorelick P B, Wilks K, Schoebelock M and Davidai G, Neurology, 2004, 63(6),1099-1101; DOI:10.1212/01.WNL.00001 38494.66691.07

7. Nikles C J, Yelland M, Del Mar C and Wilkinson D, Am J Therapeutics, 2005, 12(1), 80-91; DOI:10.1097/00045391-200501000-00011

8. $\quad$ Dr Prescott L F, Drugs, 1983, 25(3), 290-314; DOI: 10.2165/00003495-198325030-00002

9. Biuck Habibi, Mojtaba Jahanbakhshi and Mehri Abazari, J Iranian Chem Soc., 2014, 11(2), 511-521; DOI:10.1007/s13738-013-0324-3.

10. Shaidarova L G, Gedmina A V, Chelnokova I A and Budnikov G K, Russian J Appl Chem., 2011, 84(4), 620-626; DOI:10.1134/S1070427211040112

11. Atta N F, Galal A, Abu-Attia F M and Azab S M, J Mater Chem., 2011, 21, 1301513024; DOI:10.1039/c1jm11795e

12. Ying Zhang, Liqiang Luo, Yaping Ding, Xiao Liu and Zheyuan Qian, Microchimica Acta, 2010, 171(1-2),133-138; DOI: 10.1007/s00604-010-0422-1.

13. Ali Babaei, Balal Khalilzadeh and Mohammad Afrasiabi, J Appl Electrochem., 2010, 40(8), 1537-1543; DOI:10.1007/s10800-010-0131-9

14. Lourencao B C, Medeiros R A, Filho R C R, Mazo L H and Filho O F, Talanta, 2009, 78(3), 748-752; DOI:10.1016/j.talanta.2008.12.040

15. Di Berardino, S and Jasionowska, R, Am J Anal Chem., 2014, 5, 613-619. DOI:10.4236/ajac.2014.59069.

16. Maha A Sultan, Hadir M Maher, Nora Z Alzoman, Mona M Alshehri, Mohamed S Rizk, Mona S Elshahed and Ileana V Olah, J Chromatographic Sci., 2013, 51, 502510; DOI:10.1093/chromsci/bms175.

17. Eglal A A and Nada S A, J Chromatogr Sci., 2013, 51, 187-191; DOI:10.1093/ chromsci/bms125

18. Florin S, Augustin C M and Costel S, Chromatogr., 2009, 69(1-2), 151-155, DOI:10.1365/s10337-008-0822-0

19. Idris M, John C, Ghosh P, Shukla S K, Baggi T R R, J Anal Sci Technol., 2013, 4(4), 2-6. DOI:10.1186/2093-3371-4-4

20. Vignaduzzo S E and Kaufman T S, J Liquid Chromatography Related Technologies, 2013, 36, 2829-2843; DOI:10.1080/10826076.2012.717055

21. Sultana N, Arayne M S and Ali S N, Am J Anal Chem., 2013, 4, 24-33, DOI:10.4236/ajac.2013.41004

22. Gangishetty S and Verma S, ISRN Anal Chem., 2013, Article ID 948547; DOI:10.1155/2013/948547

23. Shaikh K A and Devkhile A B, J Chromatographic Sci, 2008, 46, 649-652; DOI:10.1093/chromsci/46.7.649

24. Anna Wang, Jin Sun, Haijun Feng, Shuo Gao and Zhonggui He, Chromatographia, 2008, 67(3-4), 281-285. DOI:10.1365/s10337-007-0493-2

25. Qiongfeng Liao, Zhiyong Xie, Biyan Pan, Chenchen Zhu, Meicun Yao, Xinjun Xu and Jinzhi Wan, Chromatographia, 2008, 67(9-10), 687-694; DOI:10.1365/s10337008-0560-3

26. Hao Zou, Shouhong Gao, Wansheng Chen, Yanqiang Zhong, Xuetao Jiang and Yuanying Pei, Chromatographia, 2008, 68(3-4), 251-257; DOI: 10.1365/s10337-008-0682-7

27. Lou H G, Yuan H, Ruan Z R and Jiang B, J Chromatography B, 2010, 878(7-8), 682688; DOI:10.1016/j.jchromb.2010.01.005

28. Chen X, Huang J, Kong Z and Zhong D, J Chromatography B, 2005, 817(2), 263269. DOI:10.1016/j.jchromb.2004.12.011 
29. Belal T, Awad T and Clark C R, J Chromatogr Sci., 2009, 47 (10), 849-854; DOI:10.1093/chromsci/47.10.849

30. Mallah M A, Sherazi S T H, Mahesar S A and Khaskheli A R, Am J Anal Chem., 2012, 3, 503-511, DOI:10.4236/ajac.2012.38067

31. Li Li, Yaxiang Lu, Yaping Ding, Yu Cheng, Wanichen $\mathrm{Xu}$ and Fenfen Zhang, $J$ Fluorescence, 2012, 22(2), 591-596; DOI:10.1007/s10895-011-0994-0

32. Madrakian T, Afkhami A and Mohammadnejad M, Anal Chimica Acta, 2009, 645(12), 25-29; DOI:10.1016/j.aca.2009.05.002

33. Oliva M A, Olsina R A and Masi A N, Talanta, 2005, 66(1), 229-235; DOI:10.1016/j.talanta.2004.11.015

34. Vilchez J L, Blanc R, Avidad R and Navalon A, J Pharm Biomed Anal, 1995, 13, 1119-1125. DOI: SSDI0731-7085(95)01537-X

35. Mohammad Ali Kamyabi, J Chinese Chem Soc., 2009, 56, 142-149.

36. Abbas Afkhami, Nahid Sarlak and Ali Reza Zarei, Acta Chim Slov., 2006, 53, 357-362.

37. Vu Dang Hoang, Dong Thi Ha Ly, Nguyen Huu Tho and HueMinh Thi Nguyen, Scientific World J, 2014, Article ID 313609, DOI:10.1155/2014/313609

38. Issa Y M, Zayed S I M and Habib I H I, Arabian J Chem., 2011, 4(3), 259-263; DOI:10.1016/j.arabjc.2010.06.044

39. Fatibello-Filho O and Vieira H J, Ecl Quím São Paulo, 2008, 33(2), 47-54; DOI: 10.1590/S0100-46702008000200007

40. Giriraj P and Sivakkumar T, International J Spectroscopy, 2014, Article ID 968420; DOI:10.1155/2014/968420

41. Patel D M, Sardhara B M, Thumbadiya D H and Patel C N, Pharm Methods, 2012, 3(2), 98-101; DOI:10.4103/2229-4708.103885

42. Zhan Y, Zhang Y, Li Q and Du X, J Anal Chem., 2011, 66, 215-220; DOI:10.1134/S1061934811020171

43. Mahaparale S, Telekone R S, Raut R P, Damle S S and Kasture P V, Indian J Pharm Sci., 2010, 72(1), 133-136; DOI:10.4103/0250-474X.62241

44. Khoshayand M R, Abdollahi H, Shariatpanahi M, Saadatfard A and Mohammadi A, Spectrochimica Acta Part A: Molecular Biomolecular Spectroscopy, 2008, 70(3), 491-499; DOI:10.1016/j.saa.2007.07.033

45. Sirajuddin A R, Khaskheli A, Shah M I, Bhanger A N and Mahesar S A, Spectrochimica Acta Part A: Molecular Biomolecular Spectroscopy, 2007, 68(3), 747-751; DOI:10.1016/j.saa.2006.12.055

46. Rucki R, In Florey K, (Ed.), Analytical Profile of Drug Substances, Vol. 6, Academic Press, New York, 1977, pp. 488-513.

47. Leeuwenkamp O R, Van Benneekom W P, Bult A, in: K. Florey (Ed.), Analytical Profile of Drug Substances, vol. 15, Academic Press, New York, 1986, pp. 782-789

48. Askal H F, Refaat I, Darwish I A and Marzouq M A, Spectrochimica Acta Part A: Molecular Biomolecular Spectroscopy, 2008, 69(4), 1287-1291; DOI:10.1016/j.saa.2007.07.031

49. Quan-Min Li and Lin-Xiao Gao, Anal Lett., 2008, 41(14), 2595-2607; DOI:10.1080/00032710802363354

50. Hua Zhang, Ling Li Wu, Quan Min Li and Xin Zhen Du, Chinese Chem Lett., 2008, 19(12), 1470-1474; DOI:10.1016/j.cclet.2008.09.014

51. Yan-Yan Zhan, Yan Zhang, Quan-Min Li and Xin-Zhen Du, J Chinese Chem Soc., 2010, 57(2), 230-235; DOI:10.1002/jccs.201000035 
52. Labhade S R, Labhade K R and Gaikwad V B, Chem Sci Trans.,2014, 3(4), 12541263; DOI:10.7598/cst2014.914

53. Labhade S R, Labhade K R and Gaikwad V B, Chem Sci Trans., 2015, 4(1), 37-48; DOI:10.7598/cst2015.950

54. Ramos M L, Tyson J F and Curran D J, Anal Chimica Acta, 1998, 364(1-3), 107-116; DOI:10.1016/S0003-2670(98)00146-9

55. Katz N E, Blesa M A, Olabe J A and Aymonino P J, J Inorg Nucl Chem., 1980, 42(4), 581-585; DOI:10.1016/0022-1902(80)80089-3

56. Pesez $\mathrm{M}$ and Bartos J, Colorimetric and fluorimetric analysis of organic compounds and drugs Marcel Dekker Inc., New York; 1974, 628-630. 